Brit. J. industr. Med., 1959, 16, 15.

\title{
THE RESPONSE TO HEINZ BODIES IN THE RAT
}

\author{
BY \\ PHILIP ROFE* \\ From the Industrial Hygiene Research Laboratories, Imperial Chemical Industries Limited, \\ The Frythe, Welwyn, Herts.
}

(RECEIVED FOR PUBLICATION JULY 5, 1958)

\begin{abstract}
Irregular refractile granules which occur within red blood cells were first described by Heinz in 1890. The precise nature of these bodies is unknown. The present work was undertaken in order to help to assess the significance of the presence of Heinz bodies in the blood over a considerable period.

Heinz bodies have been produced in the red blood cells of intact and splenectomized rats over relatively long periods by continuous feeding of azo geranine. The proportion of Heinzbody red blood cells quickly rose to a peak and then fell to fluctuating lower values; there was a concurrent fall in the red blood cell count and reticulocytosis. There were more Heinz-body red blood cells and a greater fall in the red blood cell count in the splenectomized animals. Large deposits of haemosiderin were present in the livers of the splenectomized animals fed the dye. Little or no haemosiderin was found in the livers of intact animals fed the dye or in those of splenectomized animals not receiving dye. Splenic hyperplasia accompanied the initial increase in Heinz-body red blood cells and remained undiminished after the level had fallen. The halftime survival of Heinz-body red blood cells transfused into normal rats was approximately one day compared with over five days in splenectomized animals. The anaemia associated with the appearance of Heinz bodies was found to be hypochromic: the mean cell haemoglobin concentration fell from $35.7 \%$ before feeding dye to $26.7 \%$ at the time of peak Heinz-body red blood cell concentration after seven days of dye feeding. With the subsequent fall in Heinz-body red blood cell level, approximately half of the deficiency in the mean cell haemoglobin concentration was replaced, despite a substantial recovery in the packed cell volume without an increase in the red cell count. Twenty days after feeding the dye had been stopped, no Heinz-body red blood cells were found, and all values had returned to normal.
\end{abstract}

The irregular refractile granules which occur within red blood cells and may measure up to $3 \mu$ in diameter were first described in detail by Heinz (1890). The precise nature of the material of Heinz bodies remains undecided, but the bulk of recent evidence, which has been reviewed by Fertman and Fertman (1955), indicates that they are composed of haemoglobin degradation products. Heinz induced these granules by administering phenyl hydrazine to animals, and since that time Heinz bodies have been primarily associated with the presence of foreign substances in the blood, notably aromatic amines and aromatic nitro compounds. However, it is clear that endogenous factors also cause Heinz bodies, for these inclusions are found

* Present address: The British Drug Houses, Ltd., Godalming, Surrey. normally in the cat (Hecht and Wingler, 1952), and in small numbers after splenectomy in the human subject (Zadek and Burg, 1930; Selwyn, 1955) and in the rat (Sorina, 1937; Rofe, 1957, unpublished). In the latter observation only some animals were affected, and in these a few Heinz bodies were seen during the first six weeks, but not later. The occurrence of Heinz bodies in the newborn human is also reported (Varadi and Hurworth, 1957).

The present work was undertaken to help to assess the significance of the presence of Heinz bodies in the blood over a relatively long period of time. A Heinz-body-forming substance has been administered continuously in the diet and the incidence of affected red cells and concurrent changes have been observed in intact and in splenectomized rats. 


\section{Methods}

Proportions of Heinz-body Red Cells and Reticulocytes and R.B.C. Count during Chronic Induction of Heinz Bodies in Intact and Splenectomized Rats.-Fifteen male rats weighing 250-300 g. were used. Seven of these were splenectomized: anaemia due to Bartonella infection developed within a week or two, but on examination four months later, normal numbers of red cells and reticulocytes were found. Heinz bodies were absent. Four splenectomized rais and four intact rats were given the Heinz-body-producing dye azo geranine* in the diet at a concentration of $1.5 \% \mathrm{w} / \mathrm{w}$ for 73 days, and the remaining rats (three splenectomized and four intact) were used as controls receiving the same diet but without dye. Tail blood from all animals was examined from time to time during this period and afterwards as follows: The incidence of Heinz-body red blood cells (H.B.R.B.C.s) was found by counting at least 500 cells stained supravitally with methyl violet: one drop of stain (half saturated in normal saline containing $0.2 \%$ citrate) on a slide, was mixed with one quarter this volume of blood on a coverslip. The R.B.C. count was made in duplicate on a sample diluted with formalin citrate (Dacie, 1956) in a red cell pipette. The same pipette was used for a given animal, and the same counting chamber (improved Neubauer ruling) was used for all. The incidence of reticulocytes was determined in at least 500 R.B.C.s smeared after supravital staining with brilliant cresyl blue (Dacie, 1956).

In order to obtain an indication of the condition of the spleens and livers of the above animals at the end of the dye-feeding period, six intact rats and six rats splenectomized for four months were killed after completing the same course of dye feeding. As a control for any liver changes which might appear solely as a result of splenectomy, five rats from which the spleens had been removed several months previously and which had not had dye were killed also. Formol-fixed sections of all the spleens and livers were treated with $\mathrm{HCl}$ and $\mathrm{K}_{4} \mathrm{Fe}(\mathrm{CN})_{6}$ to show the presence of haemosiderin and then stained with safranin; further sections were stained with haematoxylin and eosin.

Weight of Spleen during Chronic Heinz Body Induction. -Twenty-six male rats on a diet containing azo geranine $(1.5 \% \mathrm{w} / \mathrm{w})$ were killed in unselected groups of four at various times up to 43 days after the beginning of ingestion of the dye; the two animals remaining after this time were returned to a normal diet for seven days before being killed. All animals were killed by ether and were not bled: the body weights and spleen weights were then determined without delay. Eight control rats which had not had dye were treated in the same way, four being killed before and four after the course of feeding dye to allow for the intervening period of growth.

Survival of Transfused Heinz Body Blood.-In four normal male rats and three male rats splenectomized four months earlier, about one-third of the blood volume was exchanged for blood of which $90 \%$ of the cells

\footnotetext{
-Disodium salt of 8-acetamido-2-benzeneazo-1-naphthol-3:6 disulphonic acid.
}

contained Heinz bodies. The donor rats had received azo geranine $(1.5 \% \mathrm{w} / \mathrm{w})$ in the diet for six days. Blood was taken by cardiac puncture and the pooled samples stored overnight in acid citrate dextrose solution (Dacie, 1950). The recipient rats were bled and transfused via the caudal vessels. The replacement of normal blood by an approximately equal volume of Heinz-body blood gave a final incidence of H.B.R.B.C.s of about $30 \%$. The numbers in each animal were then determined from time to time until they fell below $1 \%$.

Proportion of H.B.R.B.C.s, R.B.C. Count, Packed Cell Volume, and Haemoglobin Concentration.-Ten female rats were given azo geranine in their food at a concentration of $1.5 \%(w / w)$ for 85 days. Before, during, and after this period, on a total of nine occasions, determinations were made, as follows, on tail blood taken from these rats and from nine control animals.

The proportion of H.B.R.B.C.s was found as described above. The R.B.C. count was made on a $0.02 \mathrm{ml}$. sample taken with a British Standard (B.S.) $0.02 \mathrm{ml}$. haemoglobin pipette and diluted to $4 \mathrm{ml}$. with formalin citrate (Dacie, 1956). The same individual haemocytometer chamber (improved Neubauer ruling) was used throughout the experiment for all samples: the cells on 80 small squares were counted and the mean of the counts of duplicate samples was taken. The packed cell volume (P.C.V.) was determined by centrifuging a column of blood approximately $10 \mathrm{~cm}$. long in a heparinized capillary tube for $30 \mathrm{~min}$. at $3,000 \mathrm{rev} . / \mathrm{min}$. on a maximum radius of $17 \mathrm{~cm}$. The length of the red cell column was then expressed as a percentage of the whole; the mean of duplicate values was corrected for trapped plasma, using the factor for rat blood (0.96) supplied by Huang and Bondurant (1956). Haemoglobin was estimated by the method of Haldane $(100 \%$ standard = $14.8 \mathrm{~g} . / 100 \mathrm{ml}$.). British Standard $0.02 \mathrm{ml}$. pipettes and dilution tubes were used throughout the experiment. The mean of duplicate determinations was taken. When Heinz bodies were present their release on haemolysis caused cloudiness in the haemoglobin solution. It was therefore necessary to haemolyse the blood sample in a small, sharply-pointed centrifuge tube and after spinning for $15 \mathrm{~min}$. at $3,500 \mathrm{rev}$./min. the supernatant was transferred, without loss, to the usual comparator dilution tube: this procedure was carried out on blood samples from both the control and the experimental animals when Heinz bodies were present in the latter. It was also found that after passing coal gas through the centrifuged haemoglobin solution deriving from Heinz-body blood, a faint brownish hue was discernible which was not in the control blood after identical treatment. This difference was very slight, but lest it should jeopardize the accuracy of matching in the comparator, a second pair of blood samples from each animal was estimated by the cyanmethaemoglobin method (Dacie, 1956). (The standard used was a sample of normal rat blood on which 12 determinations had been carried out by two observers, using the Haldane method.) The values obtained by this modification were close to those obtained by using the comparator, and showed no consistent difference; the results were therefore pooled, 


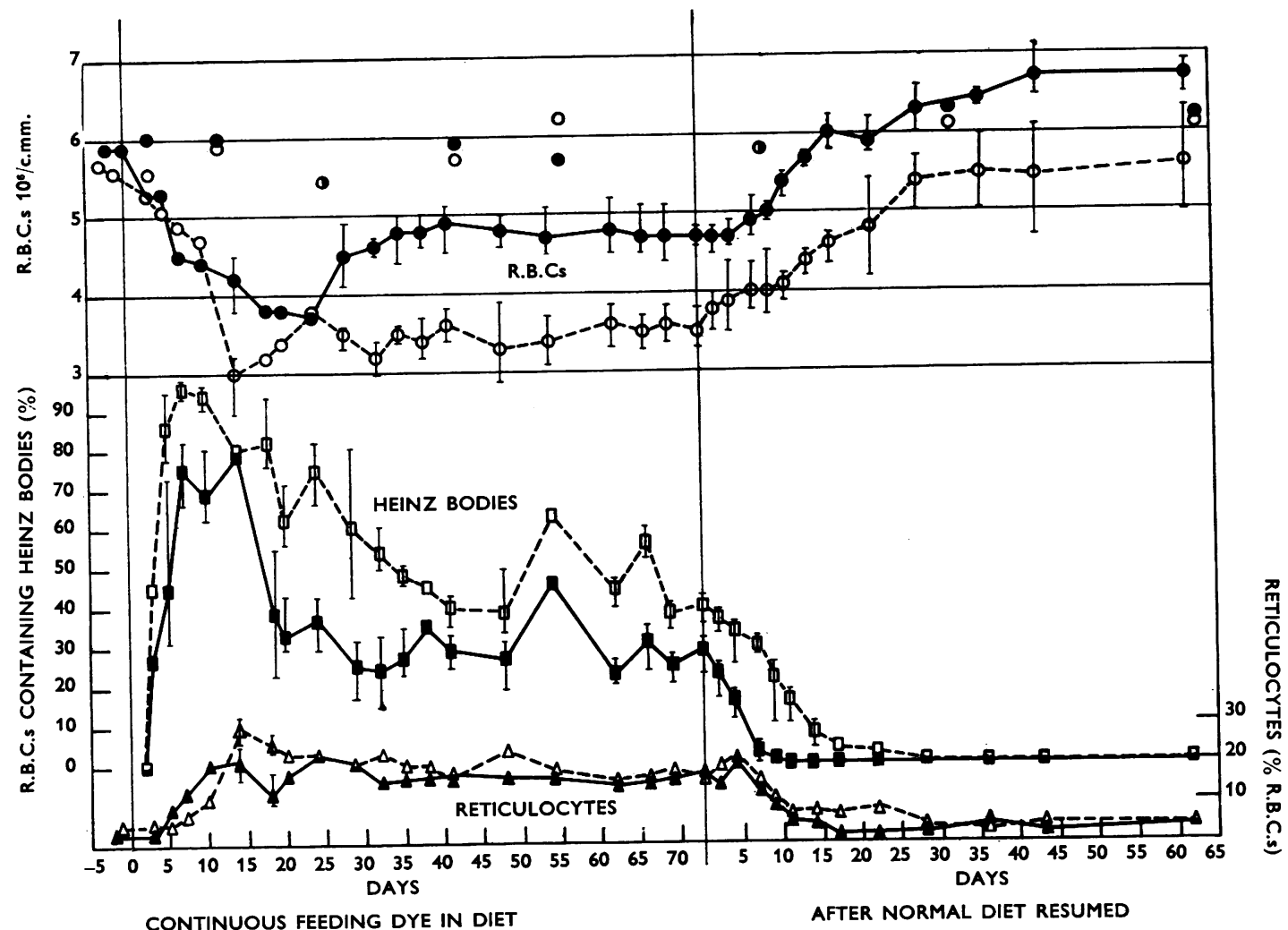

FIG 1-The R.B.C. count and the incidence of Heinz-body red cells and of reticulocytes in intact -

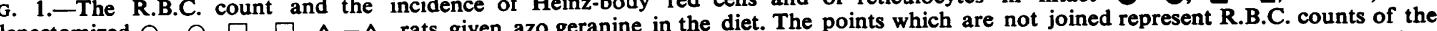
splenectomized

and the mean of the $\mathbf{4 0}$ individual determinations on the 10 experimental rats was taken as the value for the group.

\section{Results}

Proportion of Heinz-body Red Cells and Reticulocytes and R.B.C. Count during Chronic Induction of Heinz Bodies in Intact and Splenectomized rats.Figure 1 shows the changes observed. The incidence of H.B.R.B.C.s in intact rats during the course of chronic dye ingestion followed the pattern described earlier (Rofe, 1957) for other Heinz-body-producing azo dyes. This consists of a latent period, a relatively rapid rise to a peak concentration, and a slower fall to a fluctuating lower level, which is maintained so long as the dye is given. In the splenectomized animals the H.B.R.B.C.s level rises more rapidly and to a higher peak than in the intact animals; it falls more slowly and remains higher throughout the experiment. When a normal diet is resumed the intact animals remove all Heinz bodies from the circulating blood in nine days, but in the absence of the spleen this takes as long as 25 days.
Figure 1 also shows the development of anaemia and corresponding reticulocytosis. The maximum anaemia occurs in both groups some days after they reach peak H.B.R.B.C. values; during the following two weeks recovery in the intact animals is considerable but not in the splenectomized animals, and thereafter the two levels of anaemia are maintained throughout the period of feeding the dye. On returning to a normal diet, recovery proceeds at about the same rate in each group, but on reaching their pre-dosage values the intact animals show a further increase and finally establish the same difference in red cell count compared with the splenectomized group that existed during the anaemic period. The control animals, intact and splenectomized, which were not given the dye, showed no significant trend.

Of the group which were killed at the end of the dye-feeding period, the intact animals were found to have greatly enlarged spleens (see overleaf), the increase being principally in the red pulp. Microscopic examination did not indicate an increase in 


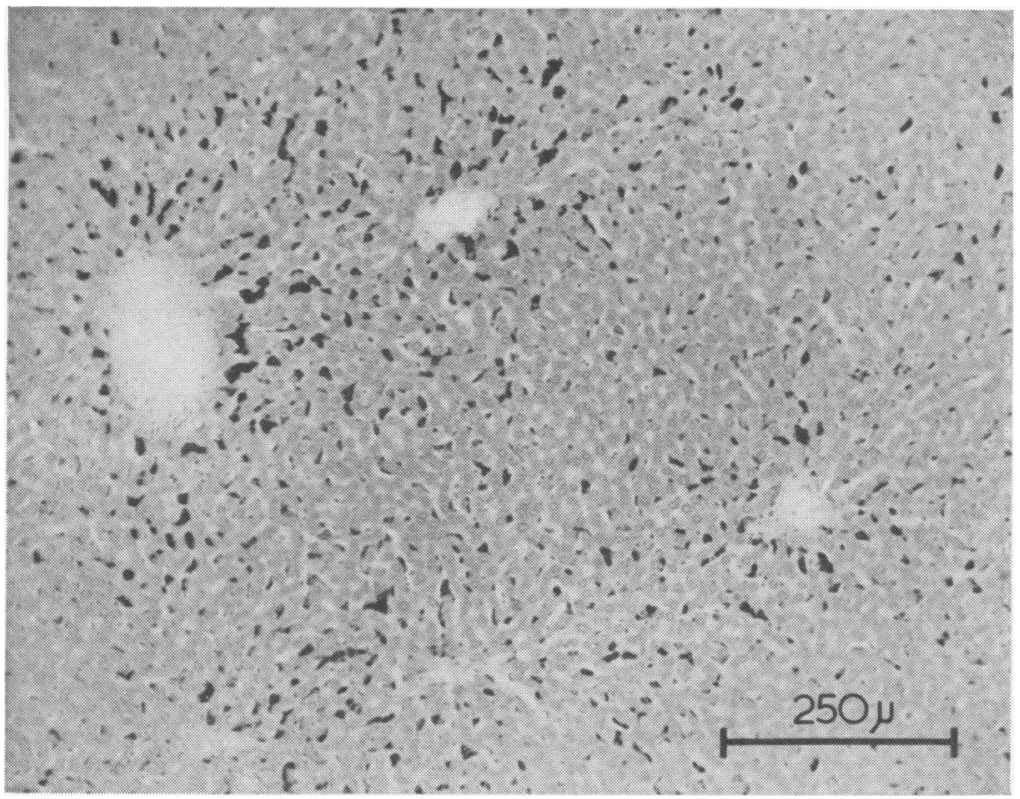

FIG. 2.-Section showing haemosiderin in the liver of a splenectomized rat after chronic induction of Heinz bodies by azo geranine. Intact animals treated in the same way and chronically splenectomized animals not given the dye, showed little or no haemosiderin. Prussian blue reaction followed by safranin.

the concentration of haemosiderin although of course the absolute amount was greatly augmented. The livers of these rats had a normal structure and contained very little haemosiderin; the livers of the splenectomized dye-fed rats, on the other hand, contained large amounts of haemosiderin (Fig. 2) but were otherwise normal. The livers of splenectomized rats which had not had dye showed little or no haemosiderin.

Spleen Weight during Chronic Heinz-body Induction.-Between the third and the fifth day of feeding the dye the average ratio of the spleen weight to the body weight of the unselected groups of four animals killed increased to more than three times the average value of the normal animals (Fig. 3). This increase began after the appearance of Heinz bodies, for on the third day, when spleen weights were normal in the animals killed, Heinz bodies were already present in $11 \%$ of their erythrocytes. The maintenance of undiminished hyperplasia is evident from the final values obtained after 43 days of Heinz-body induction (Fig. 3). The time taken to return to normal in the two remaining animals was closely similar to that taken to eliminate Heinz bodies in the experiment of Fig. 1.

Survival of Transfused Heinz-body Blood.-When approximately one-third of the blood volume was replaced by blood in which $90 \%$ of the erythrocytes contained Heinz bodies, normal rats showed virtually no Heinz bodies after four days. By contrast, the same initial proportion of Heinz bodies took 15 days to disappear from splenectomized rats. Fig. 4 shows the mean levels of surviving H.B.R.B.C.s at different times, expressed as a percentage of the initial levels determined shortly after the blood exchange.

Proportion of Heinz-body Red Blood Cells, Red Cell Count, Packed Cell Volume, and Haemoglobin Concentration.-In order to show the relative sizes of the changes which occurred, the different factors have been plotted in Fig. 5 as percentages of the respective mean values found on two occasions before feeding dye to the experimental group of animals was started.

It will be seen that after eight days, when $95 \%$ of the red cells contained Heinz bodies, the R.B.C. count was reduced by one third; a corresponding fall occurred in the P.C.V. but the haemoglobin concentration fell further, to little more than half of its original value.

Some five weeks later, despite the undiminished intake of dye, two-thirds of the R.B.C.s were free of Heinz bodies and considerable recovery had taken place in both the P.C.V. and the haemoglobin concentration: only the R.B.C. count remained unchanged. Slight increases in all values were found after a further six weeks, when the administration of azo geranine was stopped. Three weeks later the red cell count had returned to normal and the haemoglobin value had risen correspondingly. 


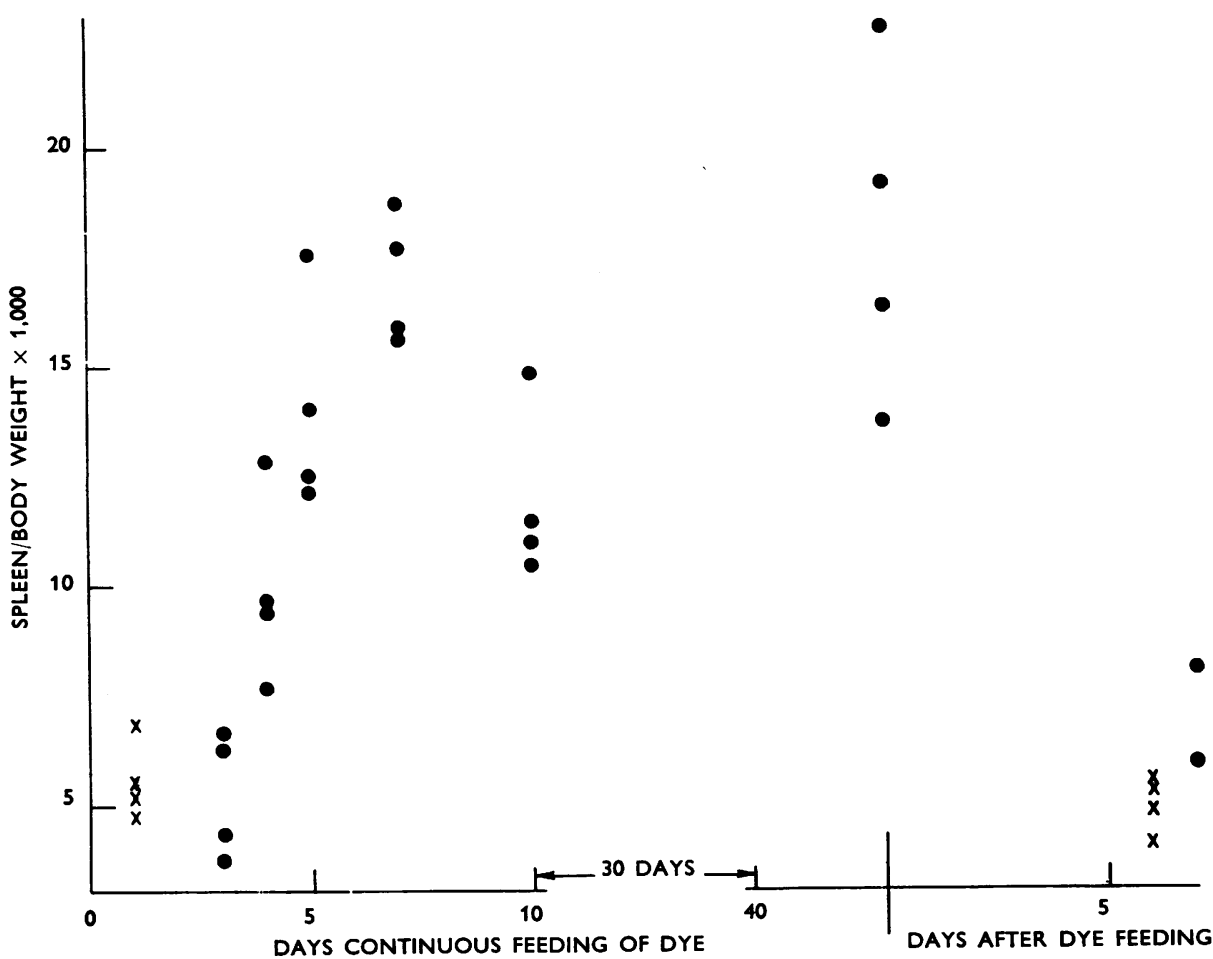

FIG. 3.-Splenic hyperplasia in rats during chronic feeding of the Heinz-body-inducing dye azo geranine each point represents the spleen/body weight ratio of an individual animal. The values for each of eight control animals are shown marked thus $x$.

A smaller increase in the P.C.V. brought this value into the normal range also. During the next 18

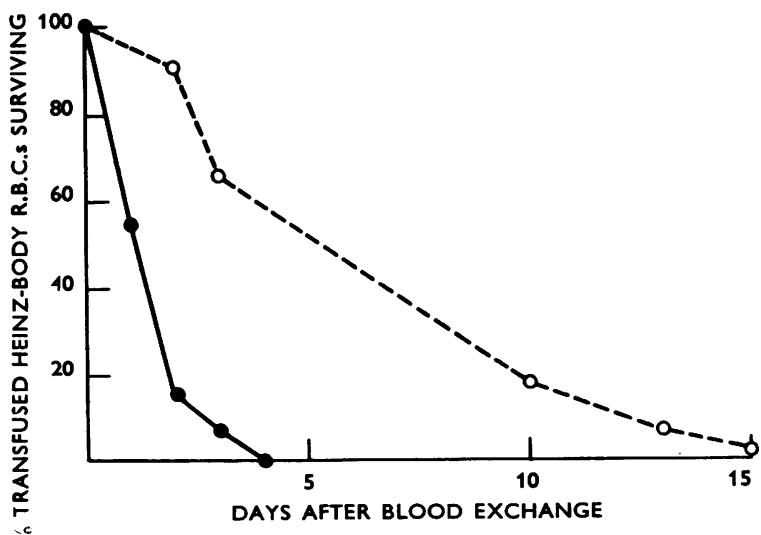

FIG. 4-The survival of transfused Heinz-body red cells in normal, - - and splenectomized, $\mathrm{O}-\mathrm{O}$, rats. The incidence of Heinz-body red cells one hour after transfusion was taken as $100 \%$ survival. weeks further determinations showed no significant differences from the control group.

\section{Discussion}

That the splenomegaly and anaemia are the response to the presence of Heinz bodies in the erythrocytes and are not due to the direct action of the dye seems probable from the following evidence. In the intact animals (Fig. 1) the anaemia varies according to the level of H.B.R.B.C.s and is not constant as is the dye intake; similarly, the splenic enlargement does not begin until after Heinz bodies are present in substantial numbers. Other dyes of very similar structure (yellow FCS, Ponceau RS, lissamine) which do not produce Heinz bodies, do not produce anaemia or splenomegaly when administered in the same molecular amounts under the same conditions.

The constancy of the daily rate of ingestion of the dye and its rapid excretion (Daniel, 1958, personal communication) provide what may be thought of as constant Heinz-body inducing conditions. 


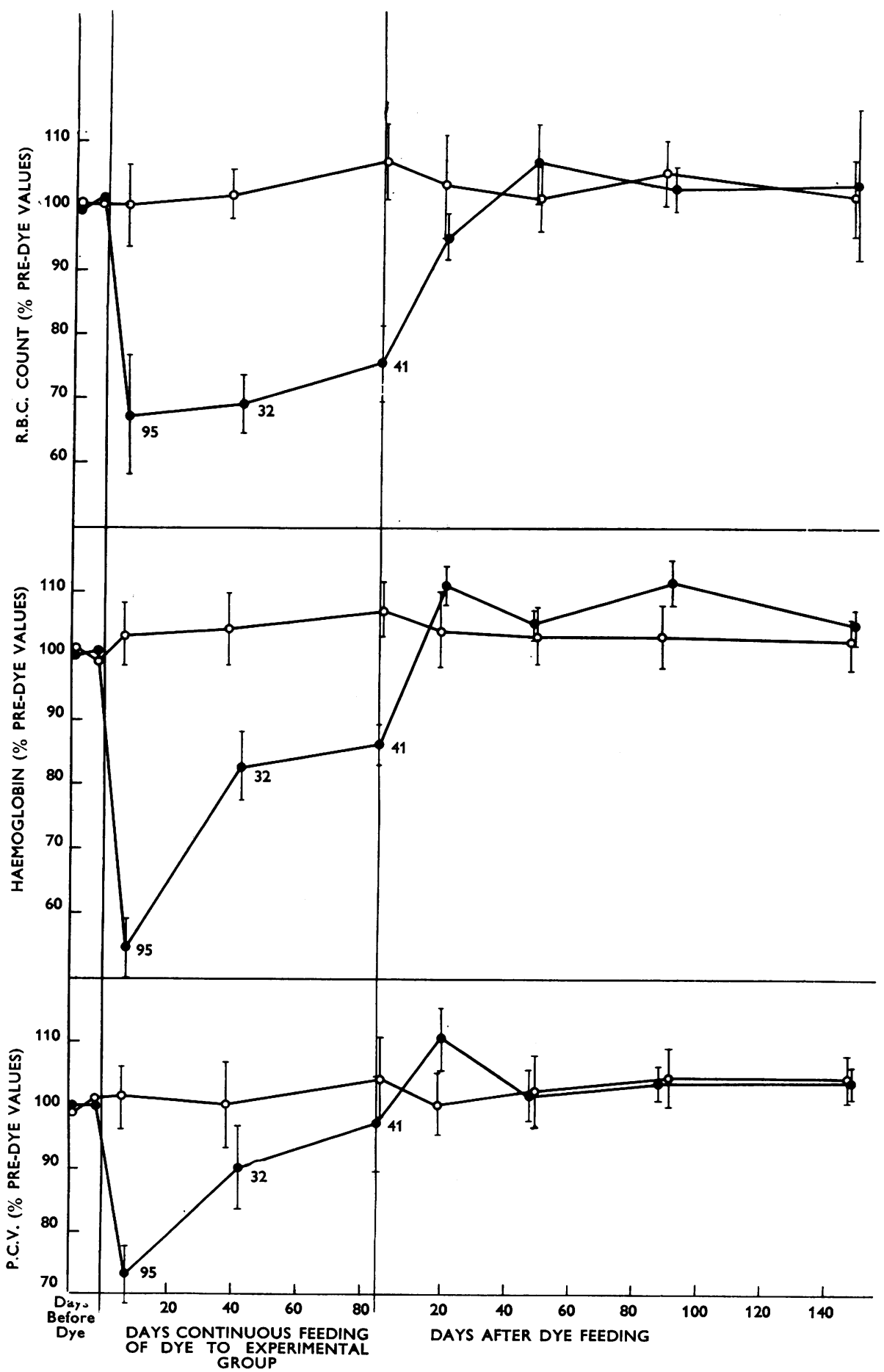

FIG. 5.-The relative changes in red cell count, haemoglobin concentration, and packed cell volume in Heinz-body anaemia. Control group of nine rats (no dye feeding) $O-O$, experimental group of 10 rats $O$ received azo geranine. Vertical lines represent \pm standard deviation. All values are directly comparable since they are expressed as percentages of the respective levels prevailing before feeding of dye to the experimental group began: these levels were as follows. R.B.C. count (10\% $\mathrm{cm}$.): control, 5.6; experimental, 5.6. Haemoglobin concentration (g./100 ml.): control, 15.5; experimental, 15.3. Packed cell volume (corrected for trapped plasma): control, $43 \cdot 1 \%$; experimental $42.9 \%$.

The numbers adjacent to some points refer to the concurrent percentage of H.B.R.B.C.s; at all other points no H.B.R.B.C.s were present. 


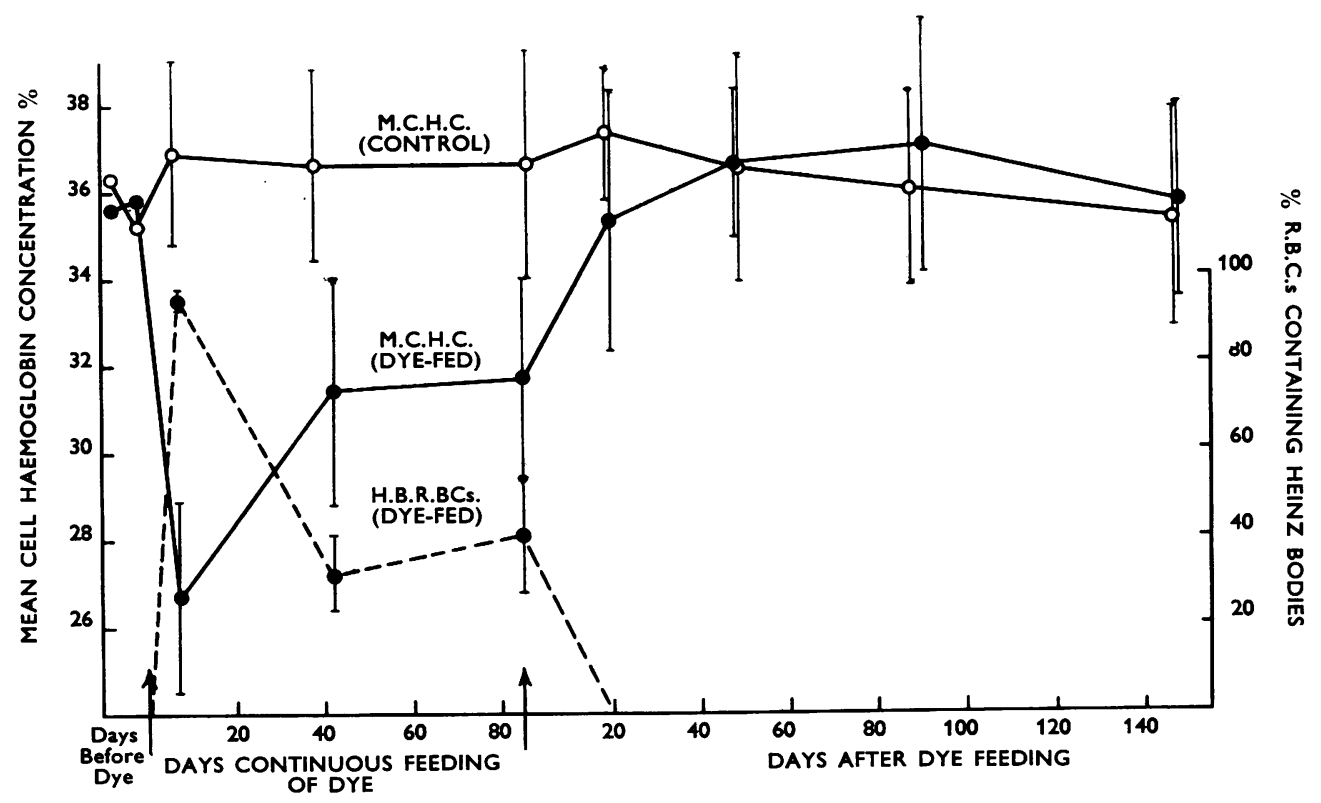

FIG. 6.-The mean cell haemoglobin concentration in nine control rats, $\bigcirc-\bigcirc$, and in 10 rats in which Heinz bodies were induced by feeding azo geranine, - Vertical lines show \pm the standard deviation.

Thus, if Heinz bodies are tending to be produced in the red cells at the same rate throughout the experiment, the observed fluctuation in their concentration (Fig. 1, intact animals) - the initial rapid rise, the brief period of high concentration, and the fall to a maintained lower level-indicate varying activity of the factors opposing an increase of Heinz bodies. At first the major factor is the removal of the affected erythrocytes from the circulating blood. This is shown by the pronounced increase in the size of the spleen and haemosiderin deposition, and the rapidly developing anaemia. Subsequently, there appears to be an increase in haemopoietic activity, for considerable recovery from the anaemia occurs despite the continued high level of blood destruction which the maintained splenomegaly (Fig. 3) presumably indicates. The mechanism, by which the H.B.R.B.C. concentration is reduced and kept at a lower level despite the unchanged conditions, thus appears to depend upon an increased turnover of red cells.

An indication of the part played by the spleen in the response to Heinz bodies is given by comparing the values for intact and splenectomized rats in Fig. 1. The absence of the spleen appears to impair the ability to remove red cells containing Heinz bodies, but the differences observed in this respect between the intact and the splenectomized cannot show the full extent of the contribution of the spleen, since in the splenectomized rats the red cell destroying function of the liver is greatly increased, as is shown by the extensive deposits of haemosiderin, which are almost absent in the intact animals and in splenectomized animals not receiving the dye. Confirmation of the importance of the spleen in the removal of H.B.R.B.C.s is given by the transfusion experiment (Fig. 4). The half-time survival of H.B.R.B.C.s (taking the numbers an hour after transfusion as $100 \%$ ) in intact rats is seen to be approximately one day, whereas in splenectomized rats it is five and a half days. This value approaches that reported for normal red cells in normal rats (Hall, Nash, and Hall, 1957). These authors injected $\mathbf{C r}^{51}$-tagged red cells into normal rats, and taking the value found one hour later as $100 \%$, obtained a half-time survival of about eight days. It thus appears that loss of the spleen results in loss of much of the ability to discriminate H.B.R.B.C.s, which are treated more as though they were normal red cells.

The greater degree of anaemia which is seen in the splenectomized animals (Fig. 1) is surprising in view of the reduced ability to destroy red cells (Fig. 4). The explanation of the partial recovery which occurs in the intact animals may perhaps lie in the development of haemopoietic function by the spleen: this has been reported in Heinz-body anaemia in rabbits (Treon, Deichmann, Sigmon, Wright, Witherup, Heyroth, Kitzmiller, and Keenan, 1949). On the other hand, Pirrie (1952), who produced chronic 
red cell stippling in guinea-pigs by daily administration of lead nitrate, found that the associated anaemia was less in splenectomized animals, and the proportion of stippled cells was higher.

Under the conditions of the present study Heinz bodies were usually found singly in the red cell and occupied about a third to a fifth of the cell diameter: they may thus be expected to represent an appreciable quantity of haemoglobin lost to the cell. That Heinz-body anaemia is markedly hypochromic is shown in Fig. 6 where the average values for mean cell haemoglobin concentration (M.C.H.C.) are shown. It will be seen that a reduction in the initial high concentration of H.B.R.B.C.s was associated with an increase of the M.C.H.C.; when six weeks later no significant change in the concentration of H.B.R.B.C.s had occurred, there had likewise been no change in the M.C.H.C.; finally, the elimination of H.B.R.B.C.s was accompanied by a rapid recovery of the normal M.C.H.C. It will also be noted that the first increase in M.C.H.C. took place despite the concurrent increase in cell size which is indicated by the increase in packed cell volume without change in the red cell count (Fig. 5).

My thanks are due to Dr. M. W. Goldblatt, C.B.E., and to Dr. A. A. B. Swan, for criticism of the manuscript. I am also indebted to Sir Roy Cameron, F.R.S., who very kindly examined some of the tissue sections. For technical assistance I am grateful to Mr. D. W. Swanston, A.I.M.L.T., and for the photograph to Mr. K. D. Cooper, F.R.M.S.

\section{REFERENCES}

Dacie, J. V. (1950). Practical Haematology, 1st ed. Churchill, London.

- (1956). Ibid, 2nd ed. Churchill, London.

Fertman, M. H., and Fertman, M. B. (1955). Medicine (Baltimore), 34, 131.

Hall, C. E., Nash, J. B., and Hall, O. (1957). Amer. J. Physiol., 190, 327.

Hecht, G., and Wingler, A. (1952). Arzneimittel-Forsch., 2, 192

Heinz, R. (1890). Quoted by Fertman, M. H., and Fertman, M. B. (1955), loc cit. Virchows Arch. path. Anat., 122, 112

Huang, K.-C., and Bondurant, J. H. (1956). Amer. J. Physiol., 185, , $\mathbf{K}$.

Pirrie, R. (1952). J. Path. Bact., 64, 211

Rofe, P. (1957). Brit. J. industr. Med., 14, 275.

Selwyn, J. G. (1955). Brit. J. Haemat., 1, 173

Sorina, E. W. (1937). Quoted by Freifeld, H, Schilowa, A., and Ludwinowsky, R. (1937): Folia haemat. (Lpz.), 56, 333 .

Treon, J. F., Deichmann, W. B., Sigmon, H. E., Wright, H., Witherup, S. O., Heyroth, F. F., Kitzmiller, K. V., and Keenan, C. (1949). J. industr. Hyg., 31, 1 .

Varadi, S., and Hurworth, E. (1957). Brit. med. J., 1, 315.

Zadek, I., and Burg, K. (1930). Folia haemat. (Lpz.), 41, 333. 